\title{
OIL PRICE SHOCKS AND EMERGING STOCK MARKETS: A GENERALIZED VAR APPROACH MAGHYEREH, Aktham ${ }^{*}$
}

\begin{abstract}
This study examines the dynamic linkages between crude oil price shocks and stock market returns in 22 emerging economies. The vector autoregression (VAR) analysis is carried on daily data for the period spanned from January 1, 1998 to April 31, 2004. This study utilized the generalized approach to forecast error variance decomposition and impulse response analysis in favor of the more traditional orthogonalized approach. Inconsistent with prior research on developed economies, the findings imply that oil shocks have no significant impact on stock index returns in emerging economies. The results also suggest that stock market returns in these economies do not rationally signal shocks in the crude oil market.
\end{abstract}

JEL Classification: G10, G12.

Keywords: Oil Prices, Emerging stock markets, VAR model.

\section{Introduction}

The oil price shock of 1973 and the subsequent recession give rise to a plethora of studies analyzing the interrelation between economic variables and oil price changes. The early studies include Pierce and Enzler (1974), Rasche and Tatom (1977), and Draby (1982), all of which documented and explained the inverse relationship between oil price increases and aggregate economic activity. Later empirical studies-such as, Hickman et al. (1987), Jones and Leiby (1996), Hooker (1999), Hammes and Wills (2003) and Leigh et al. (2003)-

\footnotetext{
* Aktham Maghyereh is Assistant Dean at the Faculty of Economics and Business Administration, the Hashemite University, Jordan. E-mail: maghyreh@hu.edu.jo
} 
confirm the inverse relationship between oil prices and aggregate economic activity.

Although the bulk of the empirical studies focus on the relation between economic activity and oil price changes, it is surprising that few studies have been conducted on the relationship between financial markets and oil price shocks- and those mainly for a few industrialized countries such as the United States, United Kingdom, Japan, and Canada. For example, Jones and Kaul (1992) examine the effect of oil prices on stock prices in the U.S. They find an effect of oil prices on aggregate real stock returns, including a lagged effect, in the period 1947 to 1991. In more recent study, Jones and Kaul (1996) test whether the reaction of international stock markets to oil shocks can be justified by current and future changes in real cash flows and/or changes in expected returns.

They find that in the postwar period, the reaction of United States and Canadian stock prices to oil shocks can be completely accounted for by the impact of these shocks on real cash flows. In contrast, the results for both the United Kingdom and Japan are not as strong. In an important study, Haung et al. (1996) examine the link between daily oil future returns and daily U.S. stock returns. The evidence suggests that oil futures returns do lead some individual oil company stock returns but oil future returns do not have much impact on general market indices. Gjerde and Saettem (1999) demonstrate that stock returns have a positive and delayed response to changes in industrial production and that the stock market responds rationally to oil price changes in the Norwegian market. Sadorsky (1999) finds that oil prices play an important role in affecting real stock returns.

Although all of these studies recognize the importance of causal relationships between oil prices and stock market returns in some industrial countries, the results from such studies cannot be generalized to other countries. Consequently, this paper extends the understanding on the dynamic relationship between oil prices and stock market return by using data from 22 emerging stock markets, which helps to fill in the gap. Specifically, this paper investigates the 
dynamic interactions between crude oil prices and stock prices in a large sample of emerging economies.

If oil plays a prominent role in an economy, one would expect changes in oil prices to be correlated with changes in stock prices. Specifically, it can be argued that if oil affects real economic activity, it will affect earnings of companies through which oil is a direct or indirect cost of operation. Thus, an increase in oil prices will cause expected earnings to decline, and this would bring about an immediate decrease in stock prices if the stock market effectively capitalizes the cash flow implications of the oil price increases. If the stock market is inefficient, stock returns might be slowly.

Given the evidence of stronger linkages between crude oil prices and stock markets in developed economies, this study considers this issue in the emerging economies. The study examines the dynamic linkages between crude oil prices and stock market returns in many emerging economies and essentially asks two questions. To what extent are price changes or returns in crude oil market lead stock returns in emerging markets? How efficiently are innovations/shocks in crude oil market transmitted to the stock markets in the emerging economies? In answering these questions it is hoped that some light may shed on the importance of the crude oil on economic output in the emerging economies. The vector autoregression (VAR) technique that is employed in this study is well suited to answering these questions.

The study utilized the generalized approach to forecast error variance decomposition and impulse response analysis in favor of the more traditional orthogonalized approach. The problem with the orthogonalized approach to variance decomposition and impulse response analysis is that the order of the variables in the VAR determines the outcome of the results. The generalized approach is invariant to the ordering of the variables in the VAR and produces one unique result. 
The paper proceeds as follows. Section 2 describes the data used in the paper. Section 3 provides an overview of the methodological issues. Section 4 presents the empiric al evidence. Section 5 provides some concluding remarks.

\section{Data}

The stock market data in this paper are obtained from Morgan Stanley Capital International (MSCI). The sample is daily encompasses the period from 1 January 1998 to 31 April 2004 and contains U.S. dollar dominated value-weighted stock market indices for the following 22 emerging countries: Argentina, Brazil, Chile, China, Czech Republic, Egypt, Greece, India, Indonesia, Jordan, Korea, Malaysia, Mexico, Morocco, Hungary, Pakistan, Philippines, Poland, South Africa, Taiwan, Thailand, and Turkey.

We choose to use the MSCI indices rather than other local stock price indices for several reasons. First, these indices are constructed on a consistent basis by the MSCI, making cross-country comparison more meaningful. Second, these indices are value-weighted reflects a substantial percentage of total market capitalization which could minimize the problem of autocorrelation in returns result from nonsynchronous trading. Third, MSCI indices are widely employed in the literature on the basis of the degree of comparability and avoidance of dual listing.

The crude oil market is the largest commodity market in the world. Total world consumption equals around 80 million barrels a day in 2003. Prices of three types of oil- Brent, West Texas Intermediate and Dubai-serve as a benchmark for other types of crude oil. Processing costs and therefore prices of oil depend on two important characteristics: sulphur content and density. Oil that has a low sulphur content ("sweet") and a low density ("light") is cheaper than process than oil that has a high sulphur content ("sour") and high density ("heavy"). For instance the price of West Texas Intermediate is generally higher than Brent oil as it is sweeter and lighter than Brent oil. Of total world oil consumption of about 80 million barrels 
a day in 2003, Brent oil serves as a benchmark for about 50 million barrels a day, West Texas Intermediate for about 15 million barrels a day and Dubai for about 15 million barrels a day.

Even though price differences do exist, crude oil prices tend to move very closely together. Since Brent oil serves as a benchmark in the crude oil market, daily closing prices of crude oil Brent are used as our primary proxy for the world price of crude oil ${ }^{1}$. The daily closing prices for crude oil Brent for the period from 1 January 1995 to 31 April 2004 are obtained from the U.S. Energy Information Administration. Finally, consistent with convention, all data used in this study has been transformed by taking the natural logarithm of the raw data.

\section{3.- Methodology}

The unrestricted vector autoregression (VAR) approach used in this study was developed by Sims (1980). The VAR was developed to account for problems with intervention and transfer function analysis. This model provides a multivariate framework where changes in a particular variable are related to changes in its own lags and to changes in other variables. The VAR treats all variables as jointly endogeneous and imposes no a priori restrictions on the structural relationships, if any, between variables being analyzed. Because the VAR expresses the dependent variables in terms of only predetermined lagged variables, the VAR model is a reduced form model.

An argument that naturally arises in the context of a VAR is whether one should use levels or first differences in the VAR. Clearly if the variable are $\mathrm{I}(0)$ processes this is not an issue. The difficultly arises, however, when the variables need to be differenced to get a stationary process, as they almost invariably do when dealing stock index data. Because of the information that is lost in

\footnotetext{
${ }^{1}$ We also estimated the results using daily for Arab light, Arab Medium, Dubai and West Texas as alternatives for the world price of oil and found these measures did not substantively affect our results.
} 
differencing, Sims (1980) and Doan (1992) have argued against it. The majority view, highlighted by Granger and Newbold (1974) and Phillips (1986) is that stationary data should be used since nonstationary data can lead to spurious regression results. Further, Toda and Yamamoto (1995) noted that conventional asymptotic theory is, in general, not applicable to hypothesis testing in levels VARs if the variables are integrated, say I(1). Thus, as the first step, the order of integration of the variables is tested. Tests for the presence of a unit root based on the work of Dickey and Fuller (1979, 1981), Perron (1988), Phillips (1987), Phillips and Perron (1988) ${ }^{2}$, and Kwiatkowski et al. $(1992)^{3}$ are used to investigate the degree of integration of the variables used in the empirical analysis. If a I(1) process does exist, the second step involves estimation of the VAR model with first differences ${ }^{4}$, otherwise VAR is estimated in levels.

To determine the appropriate number of lag length of the VAR model, the Akaike Information Criterion (AIC) and Schwarz Bayesian Criterion (SBC) are employed.

${ }^{2}$ This version of the test is an extension of the Dickey-Fuller test, which makes a semi-parametric correlation for autocorrelation and is more robust in the case of weakly autocorrelated and heteroskedastic regression residuals.

3 The KPSS procedure assumes the univariate series can be decomposed into the sum of a deterministic trend, random walk, and stationary $\mathrm{I}(0)$ disturbance and is based on a Lagrange Multiplier score testing principle. This test reverses the null and alternative hypothesis. A finding favorable to a unit root in this case requires strong evidence against the hypothesis of stationarity.

4 Earlier studies of stock returns have shown that stock returns exhibit a number of important seasonalities (e.g. January and week-end effects). These sesonalities are accounted for in our analysis by introducing dummy variables in the VAR model. Furthermore, important events in oil and equity markets during the period under investigation are the September $11^{\text {th }}$ attacks and its subsequent and the U.S. invitation of Iraq on March 19. Oil and equity markets fluctuated dramatically as a consequence of these events, therefore these events are also accounted for in the analysis by introducing dummy variables. 
Next, the generalized variance decomposition and generalized impulse response functions are employed to analysis the short-run dynamics of the variables. The purpose of the investigation is to find how each of emerging markets responds to shocks by the crude oil market. The forecast-error of generalized variance decomposition analysis reveals information about the proportion of the movements in market returns due to its "own" shocks versus shocks to the oil crude market. The dynamic responses of stock market to innovations in the crude oil market can also be traced out using the generalized impulse response analysis. Plotting the generalized impulse response functions is a particular way to explore the response of a stock market to a shock immediately or with various lags. Unlike he orthogonalized variance decomposition and impulse response functions obtained using the Choleskey factorization, the generalized variance decomposition and impulse response functions are unique solution and invariant to the ordering of the variables in the VAR (Koop et al. 1996; and Pesaran and Shin, 1998).

Another argument that arises in the context of an unrestricted VAR is whether this model should be used where the variables in the VAR are cointegrated. There is a body of literature that supports the use of a vector error correction model (VECM), or cointegrating VAR if variables are integrated, I(1). Because the cointegrating vectors bind the long run behavior of the variables, the VECM is expected to produce results in the impulse response analysis and variance decomposition that more accurately reflect the relationship between the variables than the standard unrestricted VAR.

It has been argued, however, that in the short run unrestricted VARs perform better than a cointegrating VAR (see for example, Naka and Tufte, 1997). Furthermore, Engle and Yoo (1987), Clements and Hendry (1995), and Hoffman and Rasche (1996) have shown that an unrestricted VAR is superior (in terms of forecast variance) to a restricted VECM at short horizons when the restriction is true. Naka and Tufte (1997) also studied the performance of VECMs and unrestricted VARs for impulse response analysis over the short-run and found that the performance of the two methods is 
nearly identical. This suggests that abandoning vector autoregressions for short horizon work is premature, especially when one considers their low computational burden. Although Johansen multivariate cointegration analysis is carried out in this study and cointegrating relationships founds, unrestricted VARs are used because of the short-term nature of the variance decomposition and impulse response analysis.

\section{Empirical Results}

Table 1 presents the ADF, PP, and KPSS tests for the 21 stock markets indexes as well as crude oil price in levels and first differences. The results are consistent with what has been found in most of the previous literature using such types of data. Specifically, the three tests show that the logarithm of all series has a unit root, but the first differences are stationary. Given the importance of using stationary variables, these results necessitated the use of first differenced data to carry out the VAR analysis.

As we mentioned above, the interpretation of the VAR model can brought to light through the generalized variance decomposition analysis and the estimation of the generalized impulse response functions. The results of variance decomposition are presented in Table 2. The reported numbers indicate the percentage of the forecast error in each stock market that can be attributed to innovations in the crude oil market at four different time horizons: one day, 5, 10 and 15-day ahead. The results of generalized variance decomposition analysis and generalized impulse response function provide the same conclusions regardless of order of decomposition since their estimation is independent of the ordering.

The generalized decomposition tends to suggests that the crude oil price shocks have no significant impact on any of emerging stock market under investigation. Specifically, in all cases the crude oil shocks explain less than $2 \%$ of the forecast errors variances and in 16 of the 22 emerging markets this ratio falls to less than $1 \%$. 
Table 1. Unit Root Tests

\begin{tabular}{|l|c|c|c|c|c|c|}
\hline & \multicolumn{3}{|c|}{ Level } & \multicolumn{3}{c|}{ First Difference } \\
\hline Variable & ADF & PP & KPSS & ADF & PP & $\begin{array}{c}\text { KPS } \\
\text { S }\end{array}$ \\
\hline Argentina & -1.0 & -1.1 & $2.9^{*}$ & $-16.1^{*}$ & $-36.4^{*}$ & 0.3 \\
\hline Brazil & -1.3 & -1.3 & $1.4^{*}$ & $-16.1^{*}$ & $-30.5^{*}$ & 0.2 \\
\hline China & -1.1 & -1.1 & $1.4^{*}$ & $-13.5^{*}$ & $-28.1^{*}$ & 0.3 \\
\hline Czech Rep. & -1.5 & -1.4 & $3.1^{*}$ & $-15.5^{*}$ & $-32.5^{*}$ & 0.3 \\
\hline Egypt & -1.4 & -1.2 & $3.5^{*}$ & $-15.1^{*}$ & $-30.5^{*}$ & 0.4 \\
\hline Greece & 0.1 & -0.1 & $2.4^{*}$ & $-16.8^{*}$ & $-33.5^{*}$ & 0.2 \\
\hline India & -1.0 & -0.9 & $3.1^{*}$ & $-14.6^{*}$ & $-34.4^{*}$ & 0.6 \\
\hline Indonesia & -1.1 & -1.0 & $1.3^{*}$ & $-15.1^{*}$ & $-31.5^{*}$ & 0.3 \\
\hline Jordan & -1.4 & -1.3 & $1.8^{*}$ & $-15.8^{*}$ & $-31.2^{*}$ & 0.3 \\
\hline Korea & 2.1 & 1.9 & $2.5^{*}$ & $-16.2^{*}$ & $-34.8^{*}$ & 1.2 \\
\hline Malaysia & -1.6 & -1.6 & $0.8^{*}$ & $-16.4^{*}$ & $-34.6^{*}$ & 0.1 \\
\hline Mexico & -2.2 & -2.3 & 0.1 & $-14.7^{*}$ & $-30.8^{*}$ & 0.4 \\
\hline Morocco & -2.5 & -2.5 & 0.2 & $-16.8^{*}$ & $-31.5^{*}$ & 0.1 \\
\hline Hungary & -1.7 & -1.6 & $2.9^{*}$ & $-14.6^{*}$ & $-30.7^{*}$ & 0.6 \\
\hline Pakistan & -1.0 & -0.9 & $2.7^{*}$ & $-15.2^{*}$ & $-32.8^{*}$ & 0.8 \\
\hline Philippines & -0.4 & -0.5 & $0.9^{*}$ & $-14.7^{*}$ & $-34.3^{*}$ & 0.5 \\
\hline Poland & -0.4 & -0.5 & $1.7^{*}$ & $-14.7^{*}$ & $-34.3^{*}$ & 0.3 \\
\hline South & -1.1 & -1.2 & $3.2^{*}$ & $-14.4^{*}$ & $-30.1^{*}$ & 0.2 \\
Africa & & & & & & \\
\hline Taiwan & -2.5 & -2.4 & $1.6^{*}$ & $-16.1^{*}$ & $-30.8^{*}$ & 0.1 \\
\hline Thailand & -1.7 & -1.7 & $2.5^{*}$ & $-15.3^{*}$ & $-32.8^{*}$ & 0.2 \\
\hline Turkey & -1.4 & -1.4 & $0.9^{*}$ & $-15.1^{*}$ & $-34.1^{*}$ & 0.3 \\
\hline Oil Price & -0.9 & -1.7 & $0.3^{*}$ & $-25.1^{*}$ & $-83.2^{*}$ & 0.4 \\
\hline Critical & -3.4 & -3.4 & 0.7 & -3.4 & -3.4 & 0.7 \\
Value 1\% & & & & & & \\
\hline Critical & -2.9 & -2.9 & 0.5 & -2.5 & -2.9 & 0.5 \\
Value 5\% & & & & & & \\
\hline
\end{tabular}

Notes: *and ** indicate statistical significant at the $1 \%$ and $5 \%$ level, respectively. The Augmented Dickey-Fuller (ADF) and the Phillips-Perron (PP) tested the null hypothesis of that the relevant series contains a unit root $\mathrm{I}(1)$ against the alternative that it does not, while the Kwiatowski-Pillips-Schmidt-Shin (KPSS) tested the null hypothesis that the series are I $(0)$. The critical values for the ADF and PP are obtained from Dickey-Fuller (1981) while the KPSS critical values are obtained from Kwiatkowski et al. (1992). 
Table 2. Generalized decomposition of forecast error in emerging stock markets in response to shocks in the crude oil market (\%)

\begin{tabular}{|l|c|c|c|}
\hline & 5 days & 10 days & 15 days \\
\hline Argentina & 0.622064 & 0.634352 & 0.641797 \\
\hline Brazil & 0.181891 & 0.237485 & 0.255282 \\
\hline China & 0.076167 & 0.053178 & 0.045921 \\
\hline Czech Republic & 0.169356 & 0.245609 & 0.270753 \\
\hline Egypt & 0.065641 & 0.086715 & 0.093538 \\
\hline Greece & 1.146167 & 1.393299 & 1.546380 \\
\hline India & 0.212965 & 0.731871 & 1.074984 \\
\hline Indonesia & 0.014805 & 0.036561 & 0.049455 \\
\hline Jordan & 0.172647 & 0.586863 & 0.855067 \\
\hline Korea & 1.703050 & 2.020706 & 2.028246 \\
\hline Malaysia & 1.375227 & 2.005126 & 2.384872 \\
\hline Mexico & 0.042720 & 0.178622 & 0.261737 \\
\hline Morocco & 0.022182 & 0.015533 & 0.012700 \\
\hline Hungary & 0.117332 & 0.076421 & 0.059594 \\
\hline Pakistan & 0.110283 & 0.272700 & 0.370517 \\
\hline Philippines & 0.041558 & 0.036562 & 0.034073 \\
\hline Poland & 0.041558 & 0.036562 & 0.034073 \\
\hline South Africa & 1.130735 & 1.734103 & 2.051688 \\
\hline Taiwan & 1.115818 & 1.353554 & 1.501680 \\
\hline Thailand & 0.157792 & 0.530656 & 0.817114 \\
\hline Turkey & 2.101294 & 2.381148 & 2.568307 \\
\hline & & &
\end{tabular}

Furthermore, the results show some interesting differences across countries in response to the oil market shocks, depending on the energy intensity of consumption and production. Specifically, the impact of oil shocks on stock market is highest in the largest Asian and Emerging Europe economies, as they have higher energy intensity consumption than most other emerging economies. For example, at the 15-day horizons, the percentage of error variance of a stock market explained by innovations in the crude oil market is 2.57 for Turkey followed by 2.38 for Malaysia. The Poland market appears to be the least influence by the oil market. 
Turning to the question of how effectively innovations may transmit from the oil market to the emerging stock markets, Figure 1 plots the responses of each of the twenty two emerging stock markets to a one standard error shock in the oil market. The plots in Figure 1 show that innovations in the oil market are slowly transmitted in all of the emerging stock markets with markets responding to the oil shock two day after the shock.

The speed with which the responses taper off to zero after the initial shock is felt for the most markets on day 4. Only six markets namely: Argentina, Brazil, China, Czech Republic Egypt and Greece, responses continuous until day 7 . These results may indicate that the emerging markets are inefficient in transmitting innovations/shocks in the oil market. The inefficiency in responses to a shock in the oil market is also reflected in the inaccuracy of the initial response, to the shock. However, the small size of the responses (between 0.00051 to 0.00126 , on day 2 ) reflecting that the oil market is very weak in influencing stock markets in emerging economies.

\section{5.- Conclusion}

This study examines the dynamic linkages between oil price shocks and stock market returns in 22 emerging economies. Vector autoregression (VAR) analysis is carried on daily data for the period, January 1, 1998 to April 31, 2004. This study utilized the generalized approach to forecast error variance decomposition and impulse response analysis in favor of the more traditional orthogonalized approach. Inconsistent with the pervious empirical studies in developed economies, the results from the variance decomposition analysis provided very weak evidence that there is a relationship between the crude oil price shocks and stock market returns in the emerging economies. Furthermore, the results from impulse analysis reveal that innovations in the oil market are slowly transmitted in the emerging stock markets. These results suggest that stock markets in the emerging economies are inefficient in transmission of new information of the oil market. These results may also indicate that the importance of oil price for the aggregate economy, especially in 
emerging economies, is greatly over-estimated. These results may also suggest that the stock market returns in the emerging economies do not rationally signal changes in the crude oil prices.

\section{REFERENCES}

Clements, M.P. and D.F. Hendry, 1995, "Forecasting in Cointegrated System," Journal of Applied Econometrics, 10, 127-146.

Darby, M. R., 1982, "The Price of Oil and World Inflation and Recession," American Economic Review, 72, 738-751.

Dickey, D., W.A. Fuller, 1979, "Distribution of the Estimates for Autoregressive Time Series with a Unit Root," Journal of the American Statistical Association, 74, 427-0431.

Dickey, D., W.A. Fuller, 1981, "Likelihood Ratio Statistics for Autoregressive Time Series with a Unit Root," Econometrica, 49, 1057-1072.

Doan, T. 1992, RATS User's Manual, Evanston III: Estima.

Engle, R.F. and B.S. Yoo, 1987, "Forecasting and Testing in Cointegrated Systems," Journal of Econometrics, 35, 143-159.

Granger, C.W.J and P. Newbold, 1994, "Spurious Regressions in Econometrics," Journal of Econometrics, 2, 111-120.

Hammes, D. and D. Wills, 2003, "Black Gold: The End of Bretton Woods and the Oil Price Shocks of the 1970s," Working Paper, University of Hawaii Hilo.

Hickman, B., H. Huntington, and J. Sweeney, 1987, Macroeconomic Impacts of Energy Shocks, Amsterdam: north-Holland.

Hoffman, D.L. and R.H. Rasche, 1996, "Assessing Forecast Performance in a Cointegrated System," Journal of Applied Econometrics, 11, 495-517. 
Hooker, M. 1999, "Are Qil Shocks Inflationary? Asymmetric and Nonlinear Specifications versus Changes in Regime," Working Paper, Federal Reserve Board of Governors.

Huang, R. D., R. W. Masulis, and H. R. Stoll, 1996, "Energy Shocks and Financial Markets," 27. The Journal of Future Markets, 16, 1-25.

Jones, C. M. and G. Kaul, 1992, "Oil and Stock Markets," Journal of Finance, 51, 463-491.

Jones, C. M. and G. Kaul, 1992, "Oil and Stock Markets," Working Paper, University of Michigan.

Jones, D. W. and P. Leiby, 1996, "The Macroeconomic Impacts of Oil Price Shocks: A review of the Literature and Issues," Working Paper, Oak Ridge National Laboratory.

Kwiatkowski, D., P.C.B. Phillips, P. Schmidt, and Y. Shim, 1992, "Testing the Null Hypothesis of Stationarity Against the Alternative of a Unit Root," Journal of Econometrics, 54, 159-178.

Leigh, A., J. Wolfers, and E. Zitzewitz, 2003, "What do financial Markets Think about the War of Iraq?" Working Paper, Stanford Graduate School of Business.

Naka, A. and D. Tufte, 1997, "Examining Impulse Response Functions in Cointegrated Systems," Applied Economics, 29, 15931603.

Perron, P., 1988, "Trends and Random Walks in Macroeconomic Time: Series Further Evidence from a New Approach," Journal of Economic Dynamic and Control, 12, 297-332.

Phillips, P.C.B. and P. Perron, 1988, "Testing for a Unit Root in Time Series regression," Biometrika, 75, 335-346. 
Phillips, P.C.B., 1986, "Understanding Spurious Regressions in Econometrics," Journal of Econometrics, 33, 311-340.

Phillips, P.C.B., 1987, "Time Series Regression with a Unit Root," Econometrica, 55, 277-347.

Pierce J. L., and J. E. Jared, 1974, "the Effects of External Inflationary Shocks," Brooking Papers on Economic Activity, 1, 13-61.

Rasche, R. H., and J. A. Tatom, 1977, "The effect of the New energy Regime on Economic Capacity, Production and Prices," Economic Review, 59, 2-12.

Sadorsky, P., 1999, "Oil Price Shocks and Stock Market Activity," Energy Economics, 21, 449-469.

Sims, C. A., 1980, "Macroeconomics and reality," Econometrica, 48, $1-48$.

Toda, B.H. and T. Yamanoto, 1995, "Statistical Inference in Vector Autoregressions with Possibly Int.

Journal IJAEQS published by AEEADE: http://www.usc.es/economet/eaa.htm 